\title{
DEVELOPMENT AND USE OF THE GILL UVW ANEMOMETER*
}

\author{
GERALD C. GILL
}

Dept. of Atmospheric and Oceanic Science, the University of Michigan, Ann Arbor, Mich., U.S.A.

(Received 20 January, 1975)

\begin{abstract}
A three-component anemometer, developed and refined during the past ten years, measures the three orthogonal wind-speed components directly along the instrument's three axes, $X, Y, Z$. The basic sensor for each of the three components is a light-weight helicoid propeller driving a tiny precision tachometer generator, which develops a D.C. voltage linearly proportional to the rate of turning of the.propeller and reversing in polarity when the direction of rotation reverses. Each propeller turns at a rate almost linearly proportional to the instantaneous wind speed and the cosine of the angle subtended by the wind with the axis of the propeller. Propeller sensors have a starting speed of about $0.2 \mathrm{~m} \mathrm{~s}^{-1}$; a distance constant of about $1 \mathrm{~m}$; and may be used in winds up to $30 \mathrm{~m} \mathrm{~s}^{-1}$. Over 500 of these instruments are now in use at research stations throughout the world.
\end{abstract}

\section{Introduction}

In March 1967, the writer and two of his graduate students, James Bradley and Josef Sela, presented the paper, 'The UVW Anemometer - an Instrument to Measure the three Orthogonal Wind Vectors Separately and Independently', Gill et al. (1967). The paper was well-received but was not submitted for publication as this writer thought significant improvements in the cosine response of the sensor would be made in the next two or three years. But seven years later with some improvements made in performance, but with no marked improvement in cosine response likely in the next year or two, with some 500 units of the present model in use at over 60 research stations throughout the world; and with several technical papers, Camp et al. (1970), Duchon et al. (1970), Drinkow (1972), Hicks (1972), McBean (1972), Horst (1973a, b), Fichtl and Kumar (1974), relating to its use appearing in current journals, it appears desirable to describe the development and use of this instrument.

From 1949 to the present time, the writer has attempted to develop wind instruments with improved dynamic response so that research meteorologists working on basic turbulence and diffusion studies near the ground might have better tools than the standard meteorological instruments. Fast-response bivanes, and heated thermocouple anemometers (Gill, 1956; 1957) were developed to measure simultaneously the instantaneous three components of wind flow - speed, azimuth angle, and elevation angle - at a point in space. These were fragile instruments with excellent dynamic response but were limited to fair-weather use. In 1957-58, the writer developed what became known as the Gelman-Gill Bivane, an all-weather bivane marketed by the Gelman Instrument Company.

* Presented at Third Symposium on Meteorological Observations and Instrumentation, Am. Meteorol. Soc. Washington, D.C., U.S.A, 10-13 February, 1975. 


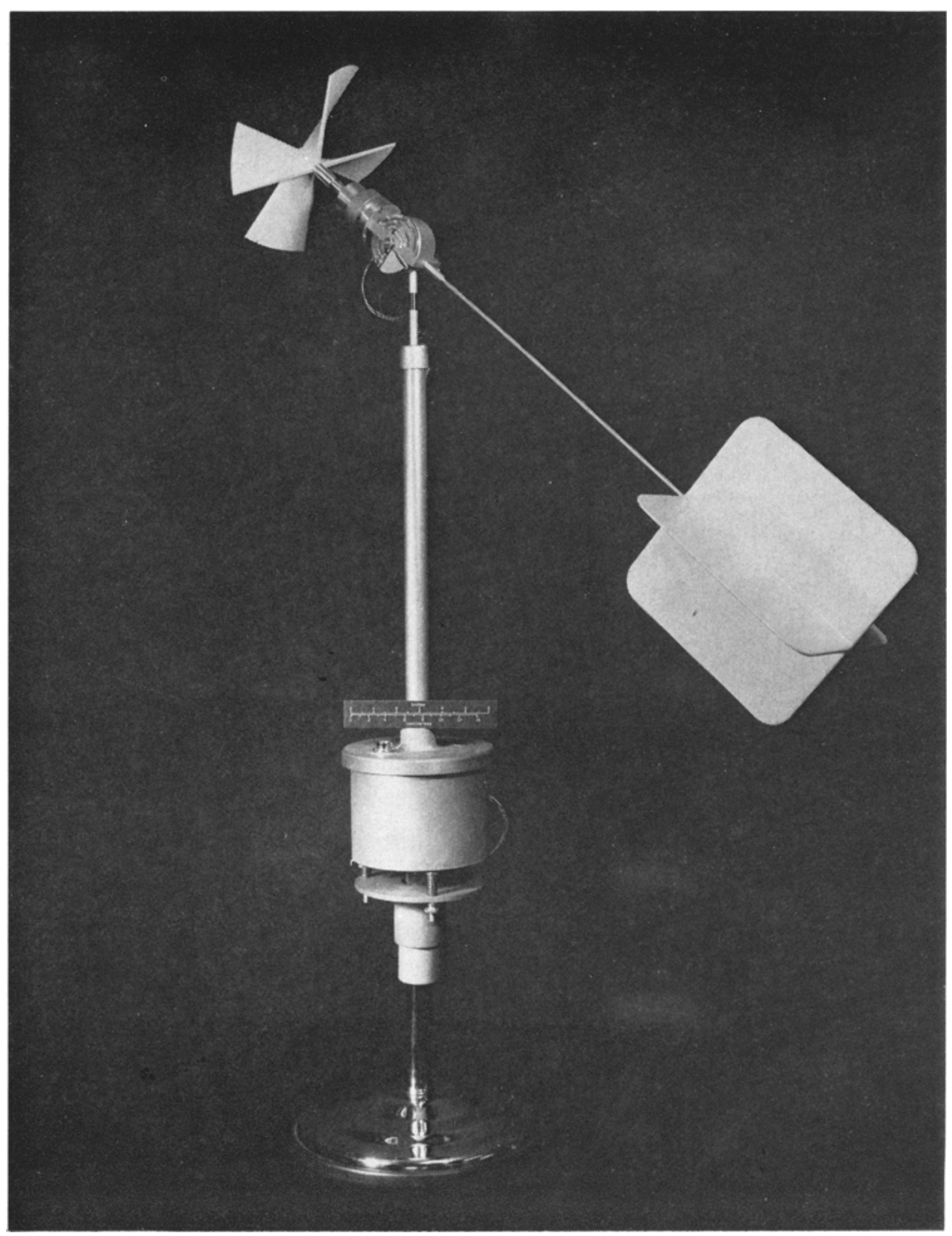

Fig. 1. Gill anemometer bivane - measures the three components of the wind: total speed, azimuth angle, and elevation angle. 


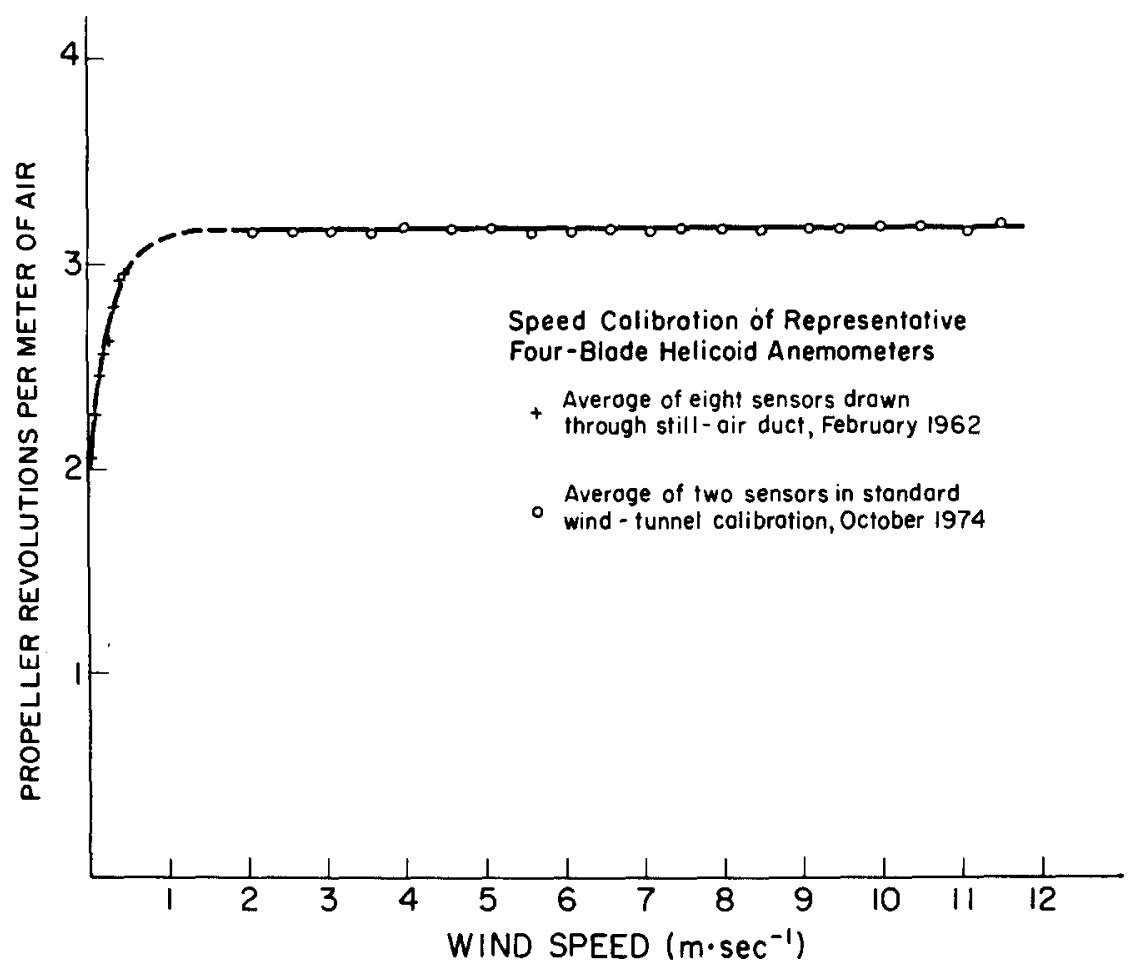

Fig. 2. Wind speed calibration of helicoid-shaped propellers. Data at speeds below $0.6 \mathrm{~m} \mathrm{~s}^{-1}$ are averages from drawing sensors along a closed duct; data at speeds above $2 \mathrm{~m} \mathrm{~s}^{-1}$ are from conventional wind-tunnel calibrations.

In 1961 with the financial help of the 'Jungle Canopy Penetration Study' (Bendix, 1963), the writer (with the invaluable help of college students) developed the anemometer-bivane shown in Figure 1. This instrument has good dynamic response. The fourblade helicoid-shaped propeller has a very low starting speed (see average data from eight sensors shown in Figure 2) and outstanding linearity of calibration over the speed range tested (same figure).

But the anemometer-bivane has one major weakness for all-weather use - rain or dew causes the vane to droop and thus gives erroneous readings of both the elevation angle of the wind and the total wind speed. Since basic turbulence and diffusion studies are not usually conducted during periods of rain, users did not complain about poor data during such periods but they were concerned about the average droop of say 5,10 or even $20^{\circ}$ caused by dew on clear nights when strong inversions developed. Being unable to overcome this weakness of the instrument in a simple way which would not cause other errors, the writer decided to test the propeller in the wind tunnel to determine the correction factors when the axis of the propeller was off from the axis of the wind by $5,10,20$ or $30^{\circ}$. The instrument response for the complete $360^{\circ}$ (instead of just 0 to $30^{\circ}$ ) was determined. A special fixture was assembled (see Figure 3) 


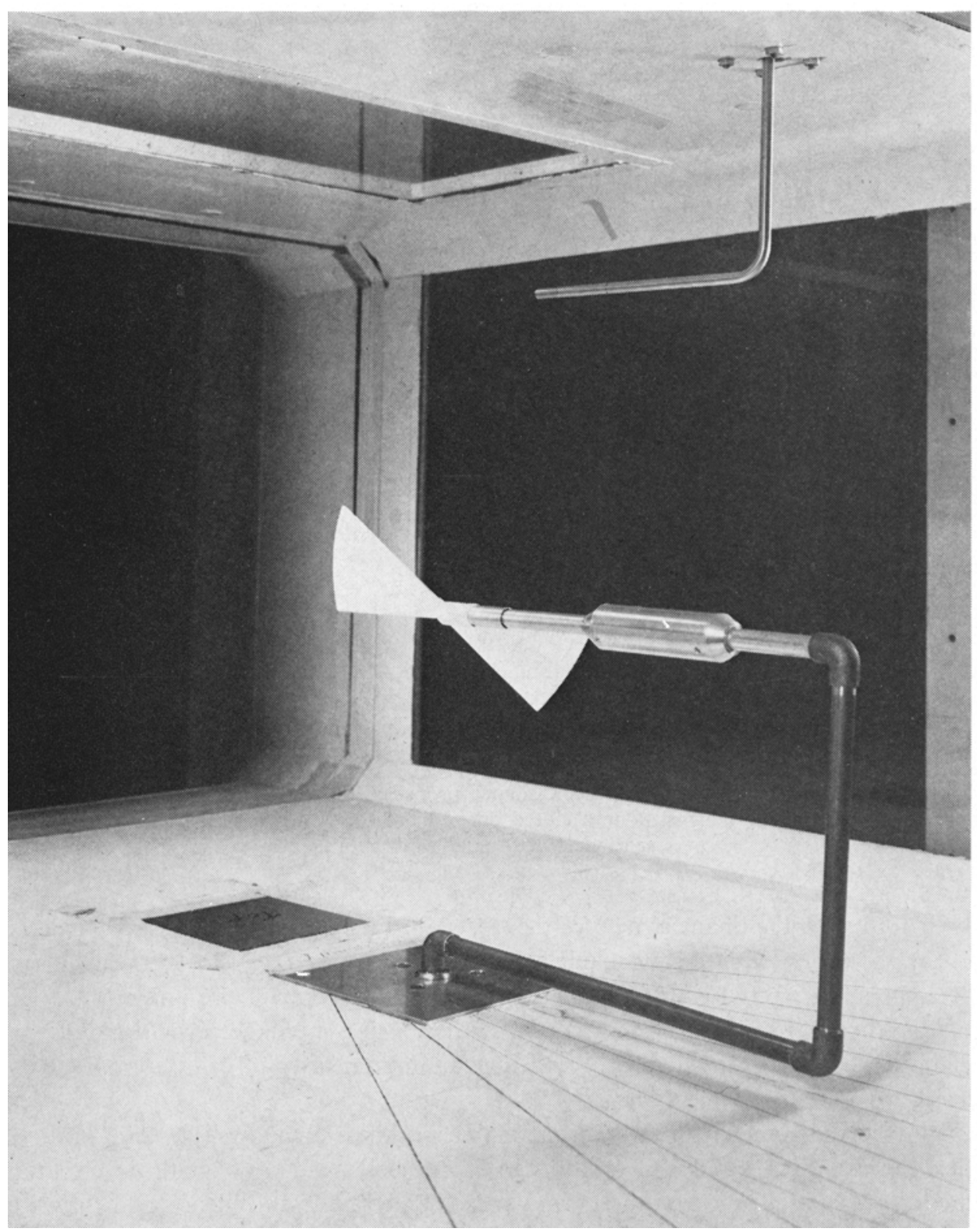

Fig. 3. Wind-tunnel fixture for determining response of propellers to winds not parallel to axis of tunnel. This fixture permitted changing the angle between axis of tunnel and axis of propeller from 0 to $\pm 180^{\circ}$ while maintaining propeller on central axis of tunnel. 


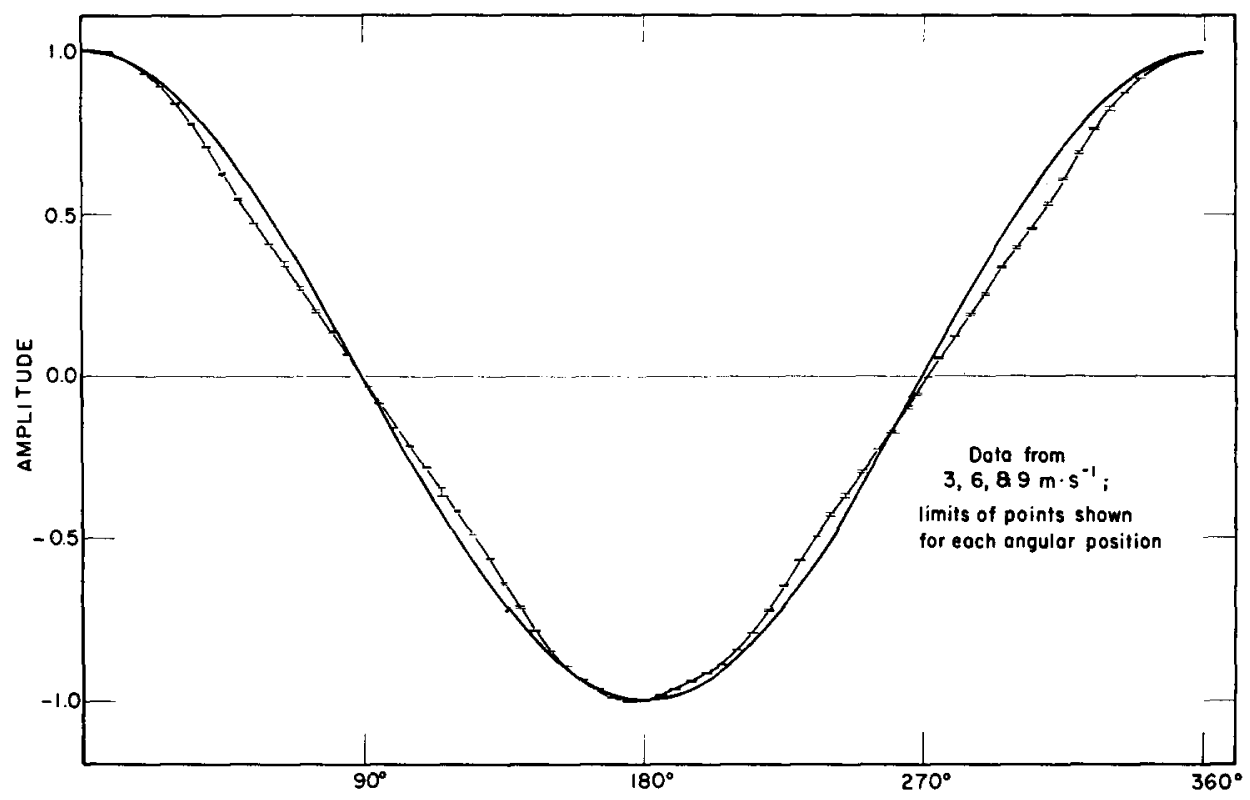

Fig. 4. Response of helicoid propeller to various angles of attack from 0 to $360^{\circ}$ at three tunnel speeds of 3,6 and $9 \mathrm{~m} \mathrm{~s}^{-1}$. Points were so close together, always within $2 \%$, that a single calibration curve was drawn. (A true cosine curve is included for comparison.)

to conduct these tests in the wind tunnel in such a way that the propeller remained essentially in the center of the wind tunnel for all azimuth positions. Tests were conducted at three tunnel speeds, 3,6 and $9 \mathrm{~m} \mathrm{~s}^{-1}$. The results are shown in Figure 4 . Also on this same graph is plotted a cosine curve - the component of the tunnel wind parallel to the axis of the propeller.

The main features determined by these tests may be summarized as follows:

1) The helicoid-shaped propeller responded very closely to the wind component parallel to its axis, (see comparison with cosine curve) i.e., the rate of turning and the direction of turning of the propeller are almost directly proportional to the component of the wind parallel to the propeller axis.

2) The response curves for the various tunnel speeds were practically identical - thus the selective response of the propeller for off-axis winds was not a function of air speed over the range of speeds tested.

Hicks (1972) conducted cosine response tests at tunnel speeds of 1,3 and $8 \mathrm{~m} \mathrm{~s}^{-1}$, and got differences in his two curves of up to $10 \%$. The writer then repeated his earlier calibrations at the above noted tunnel speeds of 3,6 and $9 \mathrm{~m} \mathrm{~s}^{-1}$, with the resulting (unchanged) curve shown in Figure 4. A single curve has been drawn, as 68 of the 72 sets of points agreed within $1 \%$ and the other 4 sets agreed within $2 \%$. The disagreement with the Hicks data is not immediately clear.

3) The response of the propeller was essentially symmetric for each of the 90-degree 
quadrants, $0-90^{\circ} ; 90-180^{\circ} ; 180-270^{\circ}$; and $270-360^{\circ}$. (This was expected, but we were pleased that the tests confirmed this).

4) The stall region for the 4-blade helicoid-shaped propeller ranged from 2 to $4^{\circ}$ depending mostly on the tunnel speed.

Result \# 1 had very great significance - if the propeller responds almost entirely to the component of the wind parallel to its axis, why not construct an instrument with three orthogonal propellers, one to measure the North-South component of the wind; a second to measure the East-West component; and the third to measure the Up-Down component - as sketched in Figure 5. The writer conceived of each propeller driving a miniature linear direct current tachometer generator, the voltage output being directly proportional to the rate of turning of the propeller, and the polarity of the voltage reversing when the direction of rotation was reversed.

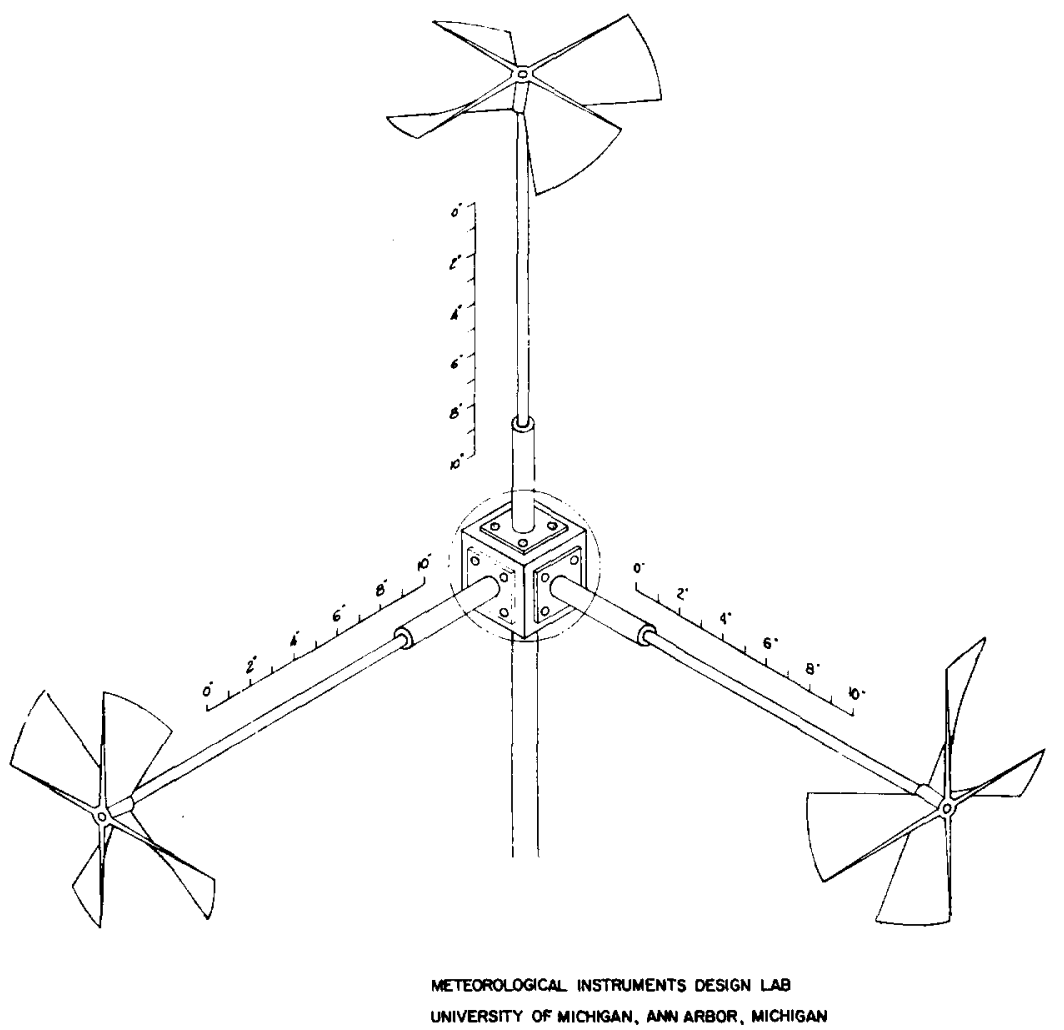

XYZ WIND COMPONENT TRANSMITTER

PROPOSED DESIGN

DESIGN - GERALD C. GILL

DRAWN BY - PETER WERNER

DATE - SEPTEMBER 23, 1962

Fig. 5. Author's sketch of proposed new three-component wind sensor. 
Thus the concept of a new instrument was born - an instrument in which three output voltages would correspond closely to the instantaneous three orthogonal components of wind speed, both in magnitude and direction, and whose operation would be almost unaffected by dew or rain.

\section{Prototype Models}

\subsection{COMPACT MODEL}

Under the writer's direction, James Bradley (a Ph.D. student) developed the detailed drawings of the new instrument and directed its fabrication. It is shown in Figure 6. Note that the new instrument followed closely the proposed design of Figure 5. The new instrument was tested in a large wind tunnel having a working section $1.7 \mathrm{~m}$ high, $2.4 \mathrm{~m}$ wide and some $6 \mathrm{~m}$ in length. The response of the $X$ and $Y$ sensors $(U$ and $V$ components) is shown in Figure 7 for horizontal flow, and corresponding to 15 and

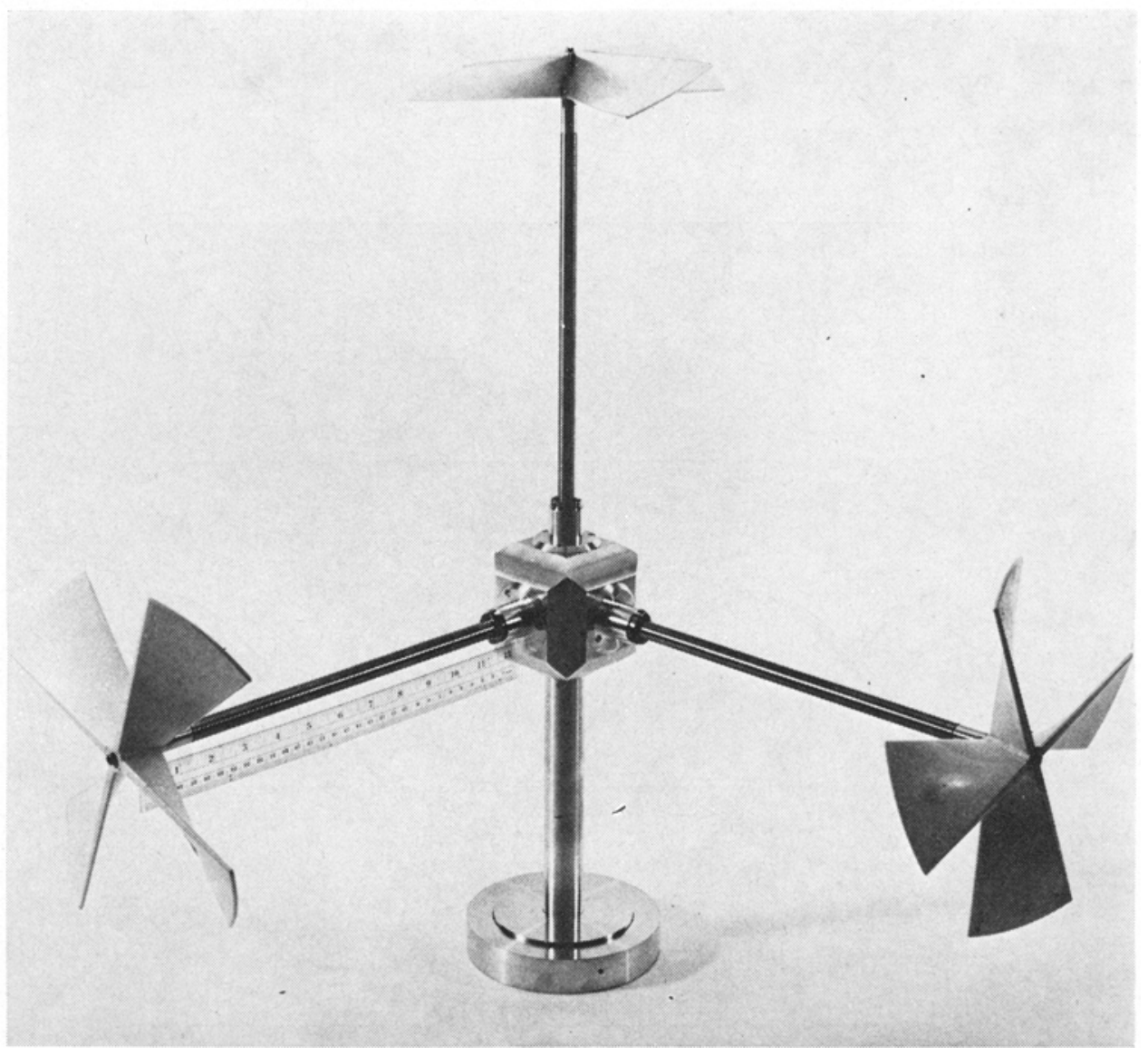

Fig. 6. First machined model of new three-component wind sensor, the 'Compact Model'. 

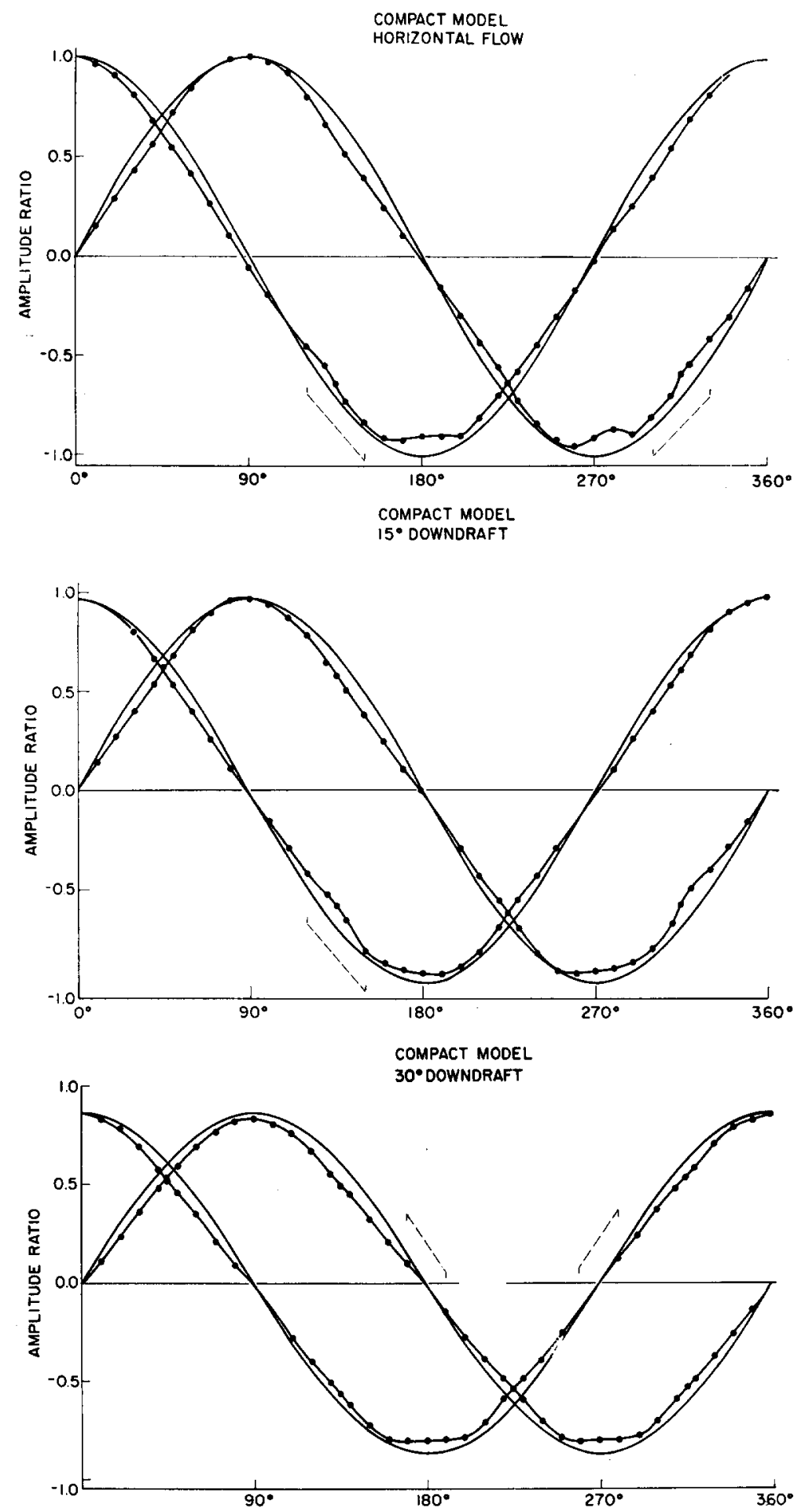

Fig. 7. Response curves of $X$ and $Y$ sensors (measuring the $U$ and $V$ wind components) of the 'Compact Model' for horizontal flow, $15^{\circ}$ downdraft, and $30^{\circ}$ downdraft wind flows. Solid curves are corresponding cosine values. 


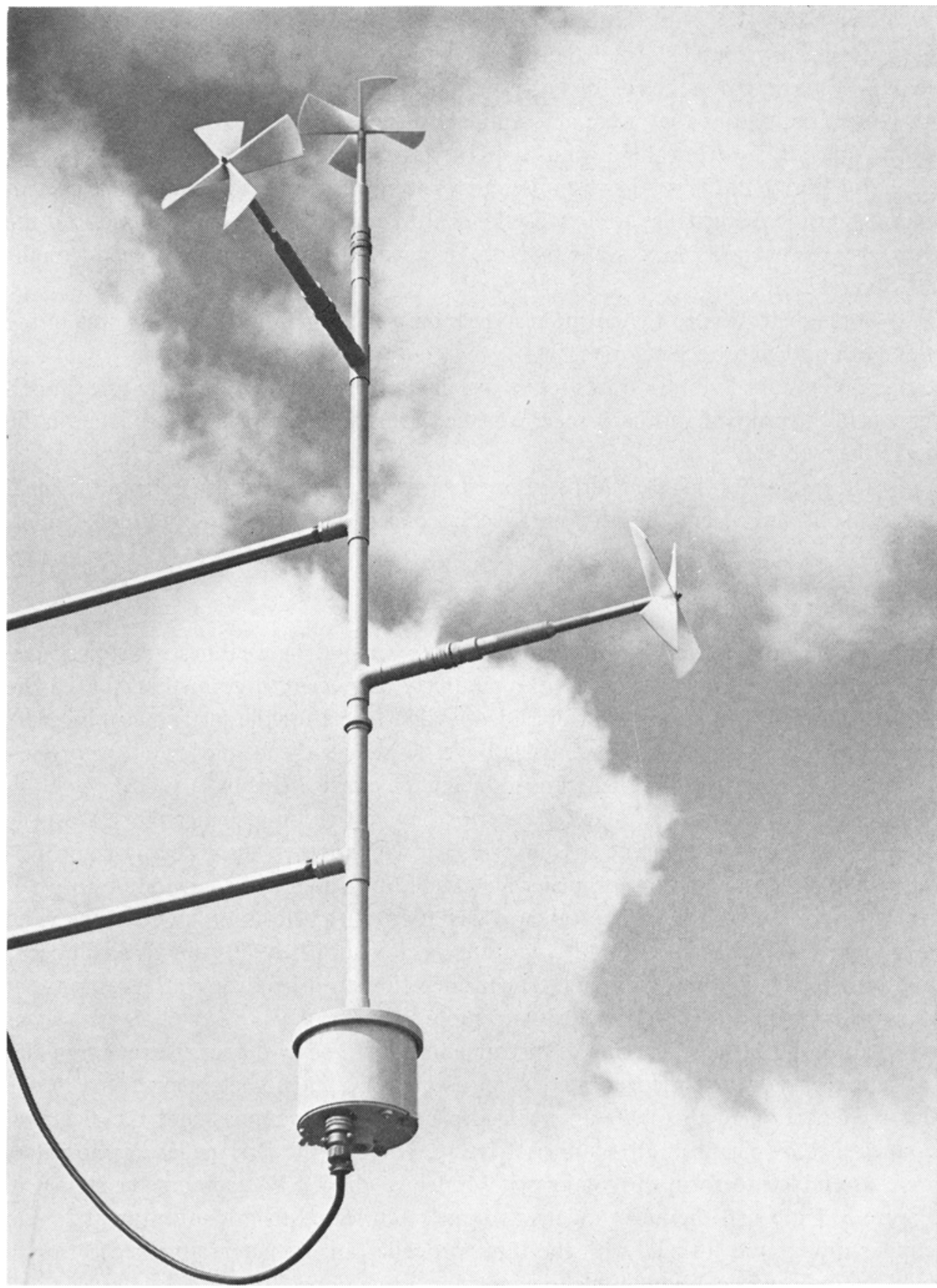

Fig. 8. 'Staggered Model' of UVW anemometer. 
$30^{\circ}$ downdrafts. (For these latter tests, the instrument was tilted forward 15, 30, and $45^{\circ}$ into the horizontal flow of the tunnel, while the instrument was rotated in $10^{\circ}$ steps.) Tests were conducted for corresponding updrafts but for brevity the graphs have been omitted as they were very similar to those for the downdrafts. The main conclusions drawn from these wind-tunnel tests were:

1) For horizontal flow, the response curves were very close to what was expected, except that the disturbance to flow by the central core of the instrument reduced the flow over the propeller in its wake by more than was hoped for - see flattened troughs at 180 and $270^{\circ}$.

2) Some distortion to the cosine response occurred when one propeller was in the wake of another propeller.

3) A mechanical vibration was set up usually in these same areas where one propeller was in the wake of another - see the dashed lines. It was always the propeller in the wake that vibrated.

4) The curves for $45^{\circ}$ downdraft showed rather marked divergence from the ideal curves (solid lines), but this did not overly concern the writer as outlined hereafter.

\subsection{STAGGeRED MODEL}

Different techniques were considered in order to remove the weaknesses listed above. It seemed most desirable to avoid the relatively large central core (that housed the three tachometer generators and provided a rigid frame for the instrument) in order to reduce the wake problem listed as 1) above. To reduce the frequency of one propeller while in the wake of another (thus reducing the effects listed in 2) and 3) above), it was decided to 'stagger' the $X$ and $Y$ sensors, having one on a higher plane than the other. To minimize interference of one propeller with another, the wake of one propeller should not reach another propeller for all elevation angles of the wind up to $\pm 30^{\circ}$ from the horizontal. (Since the standard deviation of the elevation angle of the wind rarely exceeds $10^{\circ}$, then, generally, updrafts or downdrafts of $30^{\circ}$ or more will occur less than $1 \%$ of the time, so very little consideration need be given to the response of the sensor for updrafts or downdrafts of more than $30^{\circ}$.)

To accomplish the staggering of instruments listed above, a propeller anemometer was developed which incorporated a miniature D.C. tachometer generator in the enlarged portion of the shaft and provides both the mechanical and the electrical connections by means of an Amphenol fitting. Three of these propeller anemometers were assembled to form the 'Staggered Model' of the UVW anemometer shown in Figure 8 . Note that the new model was largely fabricated from conventional $2.5-\mathrm{cm}$ copper tubing and fittings, with the three propeller anemometers attached. Prior to field testing it was calibrated in the wind tunnel mentioned above.

The resulting calibration showed improvement in cosine response for horizontal flow and for $15^{\circ}$ updraft and downdraft conditions; but no clear improvement for 30 or $45^{\circ}$ updraft and downdraft conditions. The 'staggered model' was distinctly a problem to mount and it sampled the atmosphere over too large a volume. 


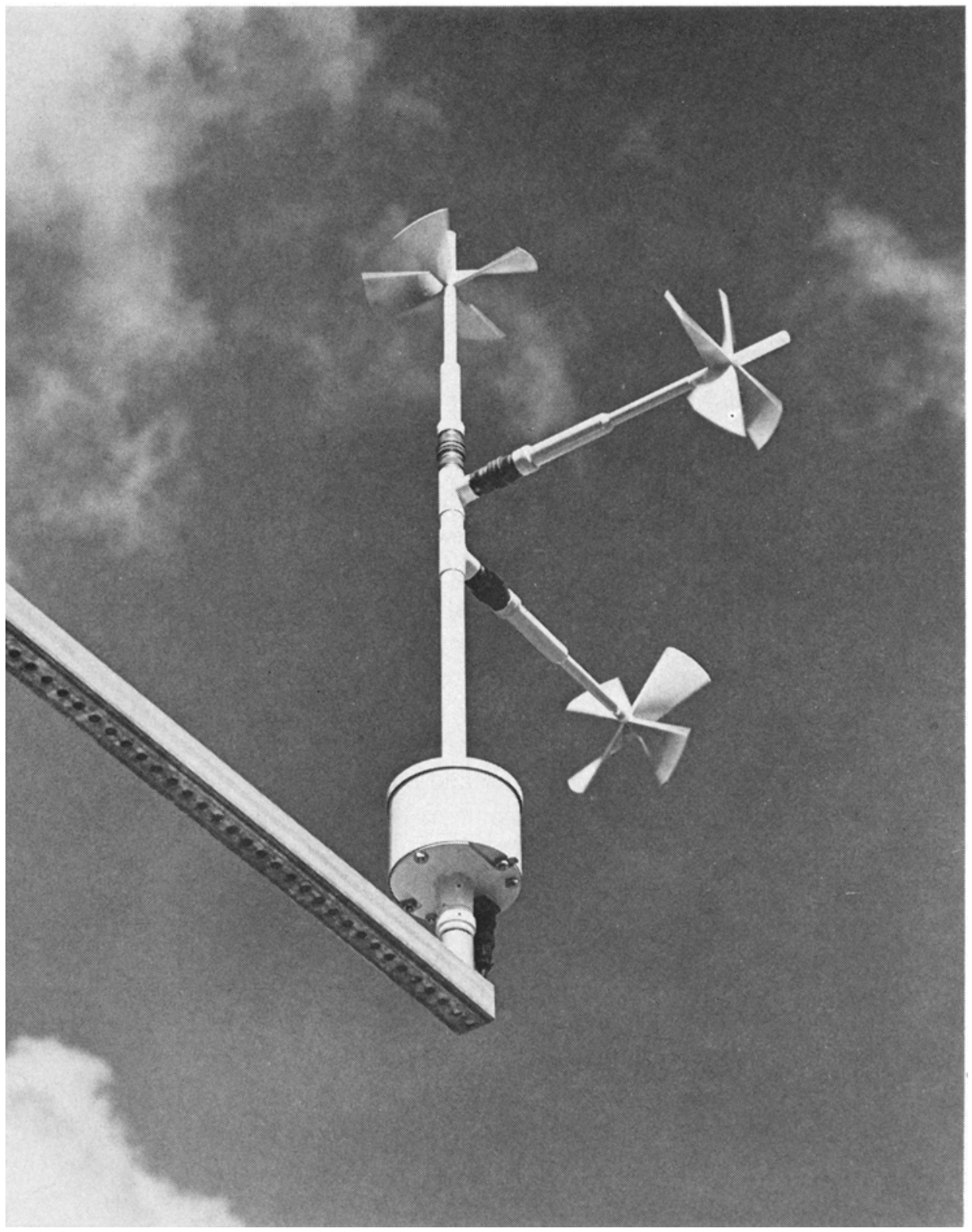

Fig. 9. Gill UVW anemometer. Sensor mounted on end of telescoping boom. 


\subsection{THIRD MODEL OF UVW ANEMOMETER}

The next model to be developed was an outgrowth of the 'compact model' and the 'staggered model' and has become known in the literature as the 'Gill UVW Anemometer'* and is shown in Figure 9. This model has remained essentially unchanged from 1966 to the present (except for some internal refinements - greater precision in construction; improved rain-shields; better bearings; and the use of shaft extensions).

\section{Current Production Model of Gill UVW Anemometer}

\subsection{General DESCRIPTION AND USE}

The overall height of the instrument is $1.14 \mathrm{~m}$; the projection of each sensor from the centerline of support is $0.48 \mathrm{~m}$ (including shaft extension); and the diameter of base housing is $0.16 \mathrm{~m}$. The net weight is about $3.5 \mathrm{~kg}$. The four-blade propellers are $23 \mathrm{~cm}$ in diameter and usually weigh $12-14 \mathrm{gm}$. The physical and electrical mounting of the sensors is by 7-pin Amphenol connectors.

The instrument is usually mounted on a telescoping boom (see Figure 9) attached to a suitable tower. The instrument is levelled and oriented before the boom is moved out to its extended position. Care should be taken to minimize tower effects on the instrument readings. The $U$ and $V$ sensors are usually aligned so that the $U$-sensor is aimed into the mean wind and the $V$-sensor measures the crosswind; or, for a more permanent installation, the $U$ and $V$ sensors are oriehted to measure directly the $\mathrm{N}-\mathrm{S}$ and E-W components, or the along-valley and cross-valley components.

The circular base of the instrument contains two main items - the electrical connections to the sensors and a small air filter system for the three sets of sensor bearings. This system is composed of a small continuous-duty blower drawing air through an oil impregnated air filter; directing the cleaned air upward through the tubular central pipe; out the three orthogonal arms; through the amphenol connectors; past the bearings; and out the propeller mount and rainshield of each sensor. By providing dust-free air with a slight oil vapor content, the trouble-free life of the bearings has been greatly extended.

Dyer et al. (1967), when developing the fluxatron, found that the use of shaft extensions on the propeller anemometer did two things:

1) made the cosine response of the sensor more symmetric for angles on each side of the stall position;

2) reduced the angle of stall from about 4 to $2^{\circ}\left( \pm 2\right.$ to $\pm 1^{\circ}$ of full stall position). At his suggestion, we have incorporated this improvement in the standard instrument.

Dr Dyer also pointed out a feature of the $W$-component sensor of the UVW anemometer (or, a single propeller anemometer mounted with its axis vertical) that had escaped us. The cosine curve in the region $90 \pm 30^{\circ}$ is very nearly a straight line - see Figure 4. The propeller anemometer response curve in this same region is also very

* R. M. Young Co. Model \#27002. 
nearly a straight line, having a slope $\frac{4}{5}$ that of the cosine curve. Since the standard deviation of elevation angle rarely exceeds $10^{\circ}$, the $\pm 30^{\circ}$ above would usually account for $99 \%$ or more of the winds encountered. By adjusting the voltage output level of the $W$-sensor by a multiplying factor of $\frac{5}{4}$, we have a much better vertical anemometer than we had realized.

The helicoid anemometer has an advantage largely overlooked in the past - it is a primary sensor, not needing calibration in a wind tunnel if its pitch is accurately known (Gill, 1974). The pitch of the UVW propellers is $0.315 \mathrm{~m}$ in $360^{\circ}$, so where bearing friction is negligible and for axial flow the propeller makes $3.17 \mathrm{rev} \mathrm{m}^{-1}$ of air, water or other fluid passing. For an instrument well-maintained, at wind speeds above $1 \mathrm{~m} \mathrm{~s}^{-1}$, bearing friction becomes negligible and need not be considered in any computations. For the very lowest of starting speeds (below $0.4 \mathrm{~m} \mathrm{~s}^{-1}$ ), a photochopper system is employed instead of the tachometer generator.

\subsection{Wind TUNNEL CALIBRATIONS}

\subsubsection{Wind Speed}

Two 4-blade propellers were calibrated in a low-speed tunnel at the University of Michigan having a working section $0.6 \times 0.9 \times 1.5 \mathrm{~m}$. The rate of turning of the propeller was very linear with wind speed down to the speeds at which pitot-tube pressures cannot be read with an accuracy of better than about $\pm 10 \%-$ around $2 \mathrm{~m} \mathrm{~s}^{-1}$. These

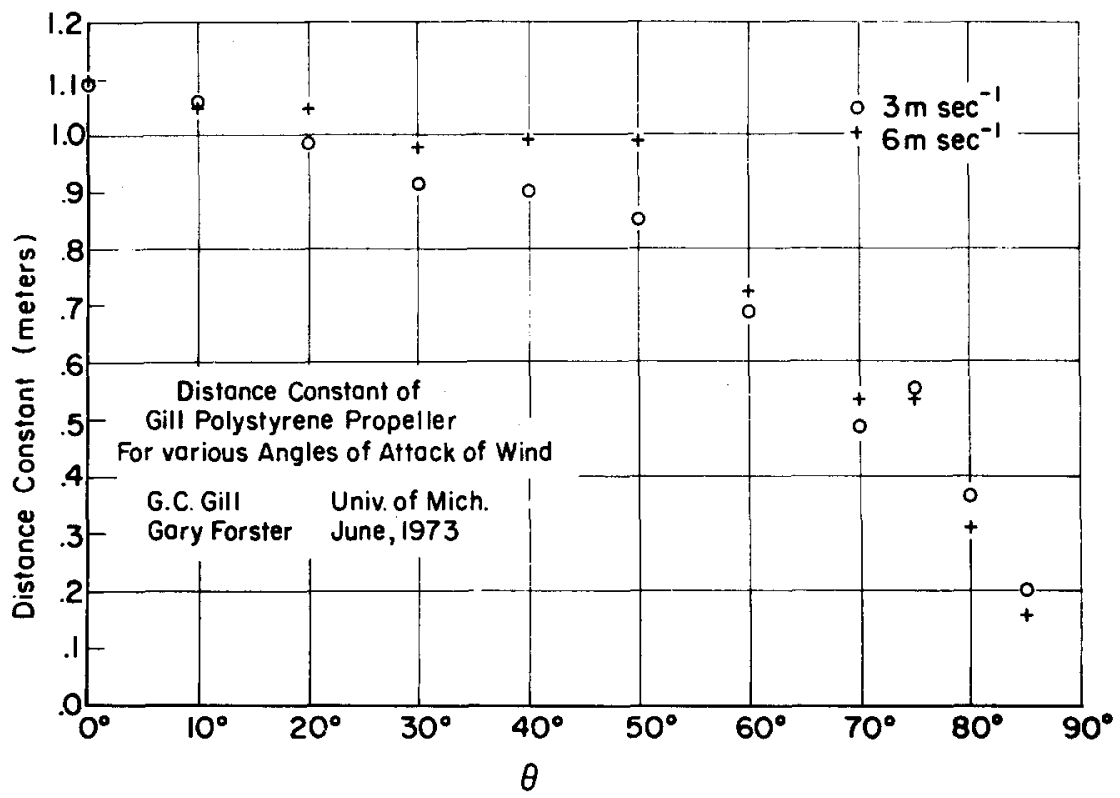

Fig. 10. Graph relating 'distance constant' to angle of wind. To conform with Hicks' (1972) notation, the distance constant, $D C$, is defined as $D C=T U \cos \theta$, where $T=$ time constant of particular test, $U=$ tunnel speed, and $\theta=$ angle between tunnel axis and propeller axis. 
calibrations are shown in the 2 to $10 \mathrm{~m} \mathrm{~s}^{-1}$ portion of Figure 2. In order to obtain accurate calibration data on the propellers at much slower speeds, a long rectangular hollow box was constructed (Bendix, 1963), $0.7 \times 0.8 \times 9 \mathrm{~m}$, and one propeller at a time was moved horizontally through the quiet air of this closed box. The propeller was moved at various steady speeds through the duct, and the rate of turning of the propeller and of distances travelled were electrically recorded. Eight such propellers were so calibrated at a series of selected speeds between 0.05 and $0.5 \mathrm{~m} \mathrm{~s}^{-1}$. These data points are plotted on the left of Figure 2. From these data, it is clear that in steady winds in the range 1.0 to $10 \mathrm{~m} \mathrm{~s}^{-1}$, the propeller makes $3.17 \mathrm{rev} \mathrm{m}^{-1}$ of air passing, and that at speeds above $1.0 \mathrm{~m} \mathrm{~s}^{-1}$, bearing friction is negligible in the normal instrument.

\subsection{2. 'Distance Constants' for Various Angles of the Wind}

The 'distance constant' of the propeller for air flow parallel to its axis was measured by the technique developed by Schubauer and Adams (1954) and in common use today (MacCready and Jex, 1964; Gill, 1967). But in the UVW anemometer, the instantaneous wind at all times makes an angle of other than $0^{\circ}$ with at least two of

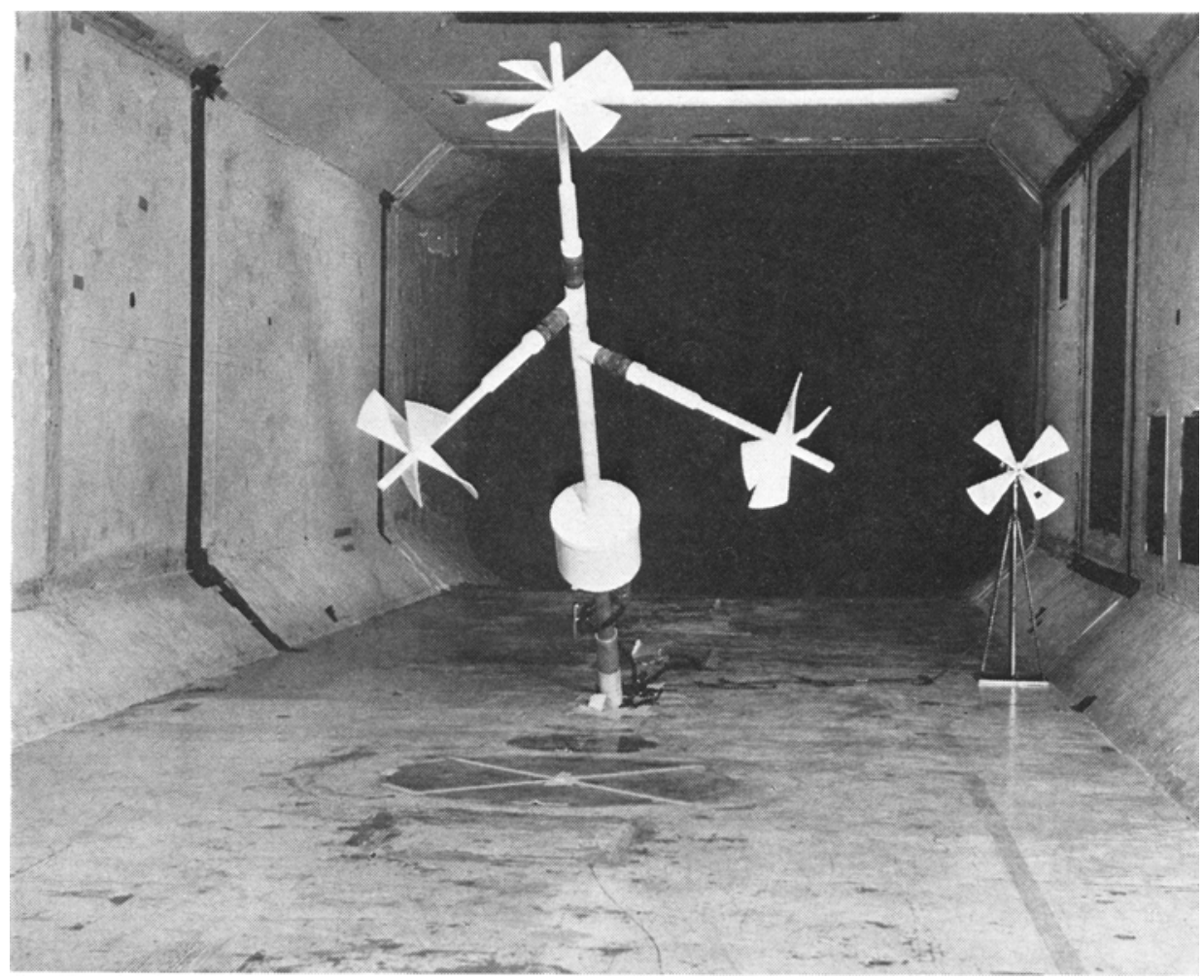

Fig. 11. Gill $U V W$ anemometer mounted in large wind tunnel ready for cosine response determinations. 

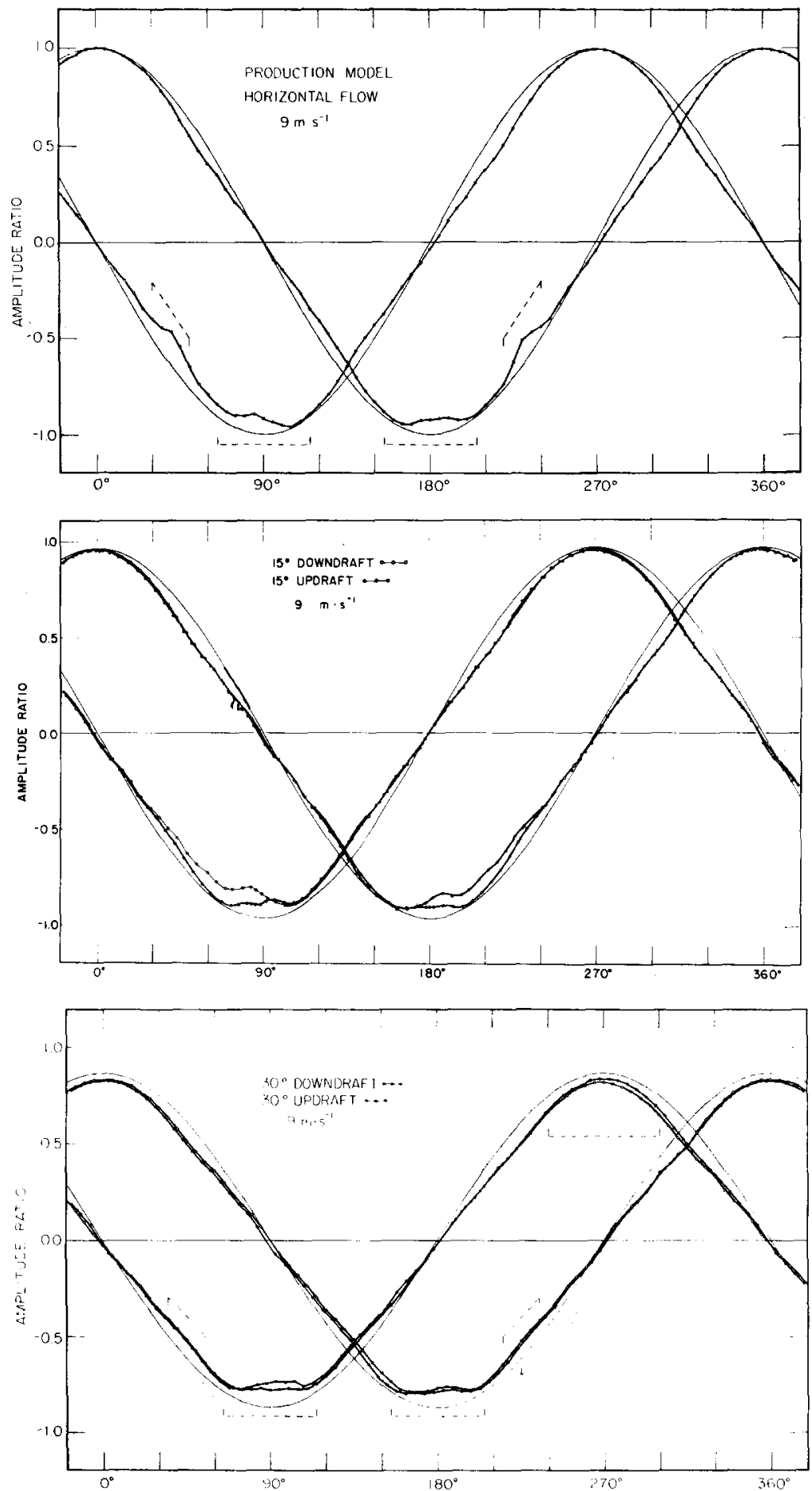

Fig. 12. Response curves of $X$ and $Y$ sensors (measuring the $U$ and $V$ wind components) of 'Gill UVW anemometer' for horizontal flow, $15^{\circ}$ updraft and downdraft, $30^{\circ}$ updraft and downdraft wind flows. Solid curves are corresponding cosine values. 
the three propellers. So the response of these propellers to off-axis winds should be measured. A fixture similar to that of Figure 3 but of much greater rigidity was constructed to determine these distance constants where the propeller axis was not parallel to the tunnel axis. The resulting calibration is shown in Figure 10.

\subsubsection{Cosine Response of Sensor}

The current model of UVW was tested in 1973 in the Low Speed Tunnel of the Dept. of Aerospace Engineering at the University of Michigan as shown in Figure 11. The sensor was tested at 3,6 and $9 \mathrm{~m} \mathrm{~s}^{-1}$, and at various tilt angles - corresponding to horizontal flow; updrafts and downdrafts of 15,30 and $45^{\circ}$. Representative cosine response curves are shown in Figure 12. These curves show that the response of the present model is slightly better than that of the original 'compact model'. However, it would be very valuable if a propeller with an improved cosine response were developed.

\subsection{ATtEMPTS TO DESIGN AND CONSTRUCT A PROPELLER WITH IMPROVED COSINE RESPONSE}

\subsubsection{Attempts by the Author}

The author has made several attempts to develop a propeller with improved cosine response, both by minor modifications to present propellers and by developing completely new molds with propellers of different pitch and different shadow areas.

Modifications to the present propeller include 2- and 6-blade (instead of 4-blade) models; decreased diameters; making the leading and trailing edges semicircular in cross-section; and other changes - but no such changes improved the cosine response.

Completely new helicoid propellers of 4-, 6- and 8-blade aluminum and 3-, 4- and 6-blade, thin-walled plastic have been designed and built - none has had response curves as close to the cosine curve as that of the original expanded polystyrene curves.

In a related development (Michelena and Gill, 1971), 4- and 6-blade propellers of much more rugged design were fabricated from fiberglass model aircraft propellers. But none of these had cosine response curves better than those of expanded polystyrene.

\subsubsection{Attempts by Other Researchers}

The writer expects that a number of researchers have tried to develop propellers with improved cosine response, but he has seen no published reports.

Christensen (1971) had a different approach to improving the cosine response and the dynamic response of the orthogonal UVW anemometer. "Guided by the fact that the instantaneous wind vector in a turbulent flow field remote from any major obstructions seldom lies outside an angular space of $30^{\circ}$ in any direction from the mean, we decided on a sensor aspect angle of $30^{\circ}$ (i.e., the axes of the three propellers are located on a conical surface having a solid angle of $30^{\circ}$ )". The instrument he designed (and 


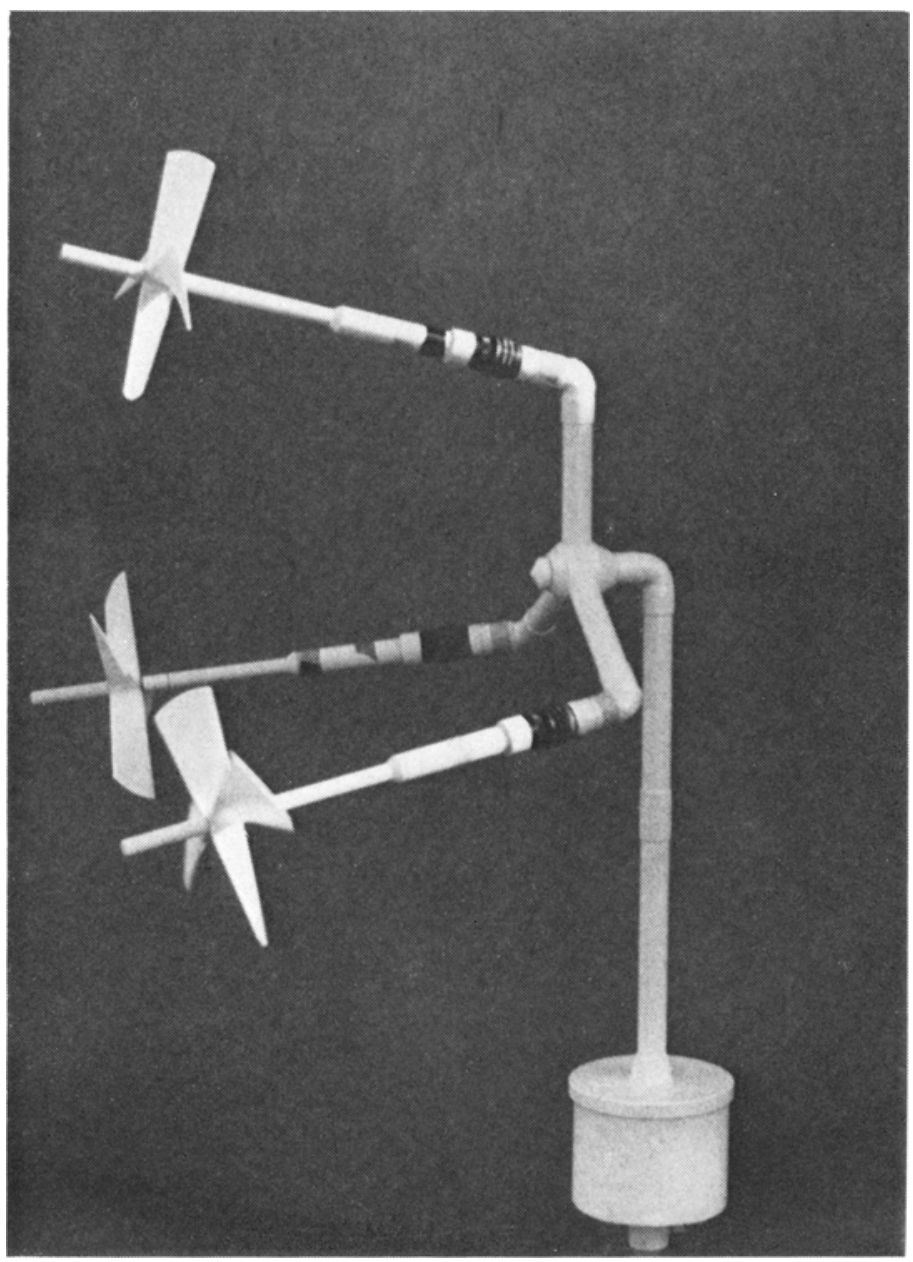

Fig. 13. Christensen's $30^{\circ}$ UVW anemometer.

built by the R. M. Young Co.) is shown in Figure 13. In use, the center axis of the cone is horizontal and aimed into the mean wind. The outputs of the three sensors were fed to an on-line computer, which through an iterative process made successive corrections to each of the three simultaneous voltages, yielding the three orthogonal wind components with greater accuracy than did the Gill UVW anemometer. However, the problems of frequent reaiming of the instrument axis into the wind, and accounting for these changes in orientation, has kept the instrument from being marketed.

So, for the foreseeable future the UVW propellers continue to be of expanded polystyrene, four-bladed and of the identical form and proportions of the present propeller. 


\subsection{CORRECTIONS TO READINGS FOR LACK OF TRUE COSINE RESPONSE}

\subsubsection{By the Author}

From the finding given above (feature (3) of Section 1), the writer (with students' help) repeated a very careful cosine response calibration of one of the UVW sensors with $7.5-\mathrm{cm}$ shaft extension. The data points for all azimuth positions 0 to $360^{\circ}$ (excepting the arc $180 \pm 30^{\circ}$ ) were plotted for a 0 to $90^{\circ}$ sector. From this curve (and the digital data from which it was plotted), a correction table in $5^{\circ}$ steps was determined for this sensor for all positions from 0 to $90^{\circ}$. If this sensor was the $U$ sensor, then the $V$ sensor would be $90^{\circ}$ out of phase with it, so that a simultaneous correction factor for the $V$ sensor could be immediately deduced. If $\theta=0^{\circ}$, the $U$ sensor would be aimed directly into the wind, and its correction factor would be 1.00 (no correction).

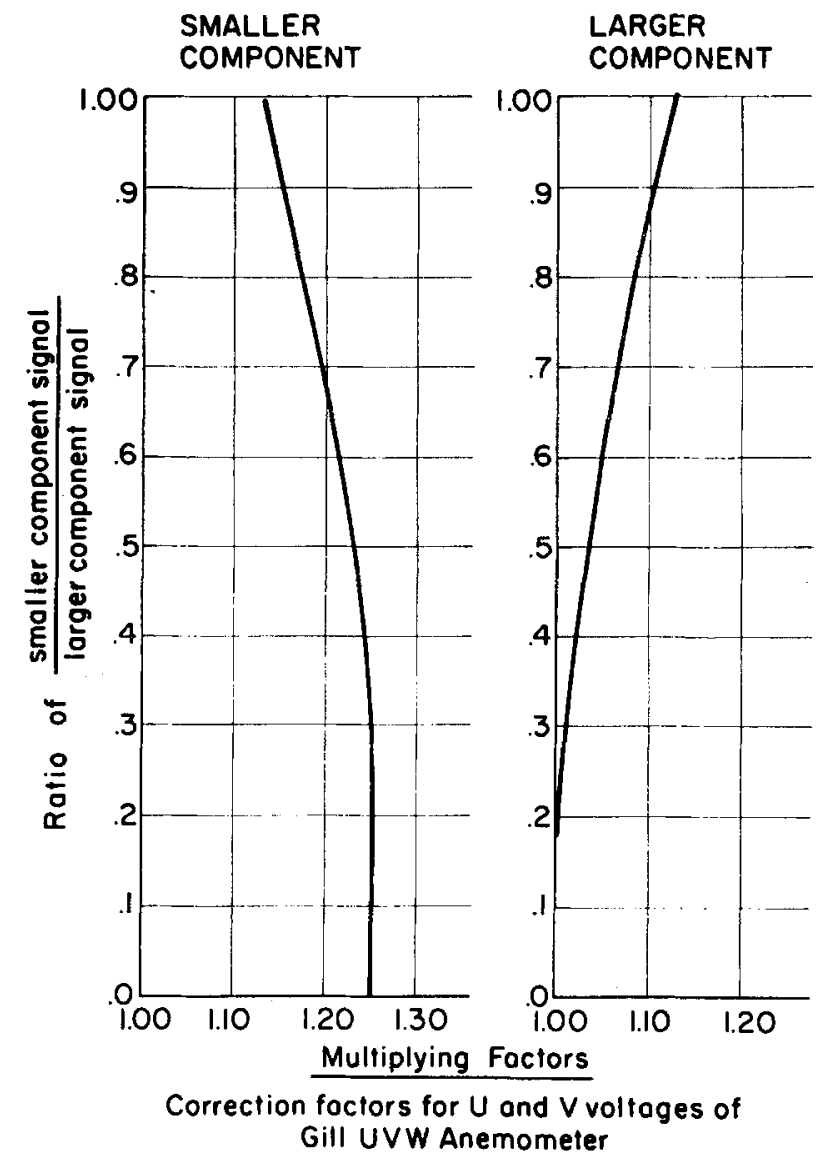

Fig. 14. Correction factors to be applied to $X$ and $Y$ sensors of UVW anemometer depending on instantaneous voltage outputs of two sensors. 
Simultaneously the $V$ sensor axis would be $-90^{\circ}$ to the wind, $\left(\theta-90^{\circ}\right)$, and the propeller would be stopped.

$$
\text { The ratio of } \frac{\text { smaller component signal }}{\text { larger component signal }}=\frac{0.00}{1.00}=0.00 \text {. }
$$

If $\theta=10^{\circ}, \cos 10^{\circ}=0.985$, the indicated signal $=0.98(3)$, (see Figure 4), the correction factor for the $U$ signal $=1.00(2)$; the $\cos \left(10-90^{\circ}\right)=0.174$; the indicated $V$ signal $=$ $=0.13(9)$ and so the correction factor for the $V$ signal $=0.174 / 0.139=1.25$. From this tabulation, the correction curves of Figure 14 and of Table I were prepared. Where an on-line computer is available, the magnitudes of the $U$ and $V$ signals may be continuously compared to get their ratio, from which the computer determines the appropriate correction factor for each signal, and the resulting signal voltages recorded.

The correction factor for the $W$ sensor that we use is a steady value of $1.25,\left(=\frac{5}{4}\right)$, for the reasons mentioned in 3.1 .

TABLE I

Summary of correction factors for horizontal component measurements by UVW anemometer.

\begin{tabular}{|c|c|c|}
\hline \multirow{3}{*}{$\begin{array}{l}\text { Ratio of: } \\
\text { smaller component signal } \\
\text { larger component signal }\end{array}$} & \multicolumn{2}{|c|}{ Correction factors ${ }^{\mathfrak{a}}$} \\
\hline & \multirow{2}{*}{$\begin{array}{l}\text { Larger } \\
\text { signal }\end{array}$} & \multirow{2}{*}{$\begin{array}{l}\text { Smaller } \\
\text { signal }\end{array}$} \\
\hline & & \\
\hline 0.00 & 1.000 & 1.250 \\
\hline 0.05 & 1.000 & 1.250 \\
\hline 0.10 & 1.000 & 1.250 \\
\hline 0.15 & 1.002 & 1.250 \\
\hline 0.20 & 1.004 & 1.250 \\
\hline 0.25 & 1.008 & 1.250 \\
\hline 0.30 & 1.013 & 1.248 \\
\hline 0.35 & 1.018 & 1.245 \\
\hline 0.40 & 1.024 & 1.240 \\
\hline 0.45 & 1.030 & 1.235 \\
\hline 0.50 & 1.037 & 1.228 \\
\hline 0.55 & 1.043 & 1.220 \\
\hline 0.60 & 1.049 & 1.212 \\
\hline 0.65 & 1.057 & 1.203 \\
\hline 0.70 & 1.066 & 1.193 \\
\hline 0.75 & 1.075 & 1.183 \\
\hline 0.80 & 1.083 & 1.173 \\
\hline 0.85 & 1.093 & 1.163 \\
\hline 0.90 & 1.103 & 1.152 \\
\hline 0.95 & 1.115 & 1.141 \\
\hline 1.00 & 1.130 & 1.130 \\
\hline
\end{tabular}

a The data have been given to three decimal places for sake of possible use in a computer. The third decimal place is always in doubt, and for some regions, the second decimal place may also be so. 


\subsubsection{Work by Others}

Using the cosine response calibration curves supplied by R. M. Young Co., Drinkow (1972) made a somewhat similar analysis to that indicated above, and developed a correction algorithm for the simultaneous $U$ and $V$ sensor voltages. By some simpling techniques, he greatly reduced the use of computer time for an on-line computer, so that several UVW sensors could be used and analyzed simultaneously.

Both the frequency response as well the as cosine response of the $W$ component sensor were carefully studied by McBean (1972). His findings for cosine response were similar to the authors. His power spectra data showed that good dynamic response was obtained with the propellers for gust wavelengths of $12 \mathrm{~m}$ and greater, but for shorter wavelengths, the response of the propellers rapidly dropped off. This is in good agreement with earlier published data on these propellers (Gill, 1967, Figure 5).

Horst $(1973 \mathrm{a}, \mathrm{b})$ experimented with the $U V W$ anemometers. He and his colleagues tried to improve the overall response of the instrument by incorporating a fourth sensor at an intermediate angle in the orthogonal array. Unfortunately a significant improvement in performance did not occur so he prepared an algorithm correction (Horst, 1973b), rather similar to Drinkow's, and used this to correct his data output.

Fichtl and Kumar (1974) have made an in-depth mathematical analysis of the response of the $W$ sensor to turbulent flow. Details of their findings are beyond the scope of this paper.

\section{Conclusions}

A new instrument of rather novel design has been developed to measure simultaneously the three orthogonal components of wind flow, $U, V$, and $W$. The instrument is designed for continuous use at locations where the wind speed is not expected to exceed about $25 \mathrm{~m} \mathrm{~s}^{-1}$. The three sensor outputs of the instrument are usually voltages which vary in magnitude and sign with the speed and direction of the wind components. Data are usually recorded on a magnetic tape recorder of 3 or more channels. For some studies, no correction is applied to the three $U, V$, and $W$ component voltages, but where greater accuracy is desired, a computer may be used to compare the $U, V$ and $W$ components simultaneously and amplify these by the appropriate amounts. The instrument measures gust wavelengths of $12 \mathrm{~m}$ and greater with good accuracy.

\section{References}

Bendix Systems Division: 1963, 'Meteorological Sensors and Recorders'. Jungle Canopy Penetration, Vol. III, Report \#BSC-36176, 5-15 to 5-64.

Camp, D. W., Turner, R. E., and Gilchrist, L. P. : 1970, 'Response tests of Cup, Vane, and Propeller Wind Sensors', J. Geophys. Res. 75, 5265-5270.

Christensen, O.: 1971, 'Wind Velocity Sensing by Means of Four-Bladed Helicoid Propellers', Univ. of Mich., Dept. of Meteorology and Oceanography Report, 100 pp.

Drinkow, D.: 1972, 'A Solution to the Paired Gill-Anemometer Response Function', J. Appl. Meteorol. 11, 76-80.

Duchon, C. E., Brock, F. V., Armendariz, M., and Horn, J. D.: 1970, UVW Anemometer Dynamic Performance Study, U.S. Army Electronics Command, ECOM Report \#5440, 34 pp. 
Dyer, A. J., Hicks, B. B., and King, K. M.: 1967, 'The Fluxatron - a Revised Approach to the Measurement of Eddy Fluxes in the Lower Atmosphere', J. Appl. Meteorol. 6, 408-413.

Fichtl, G. H. and Kumar, P.: 1974, 'The Response of a Propeller Anemometer to Turbulent Flow with the Mean Wind Vector Perpendicular to the Axis of Rotation', Boundary-Layer Meteorol. 6, 363-379.

Gill, G. C.: 1956, 'M.I.T. Bivane, Potentiometer Type'. Encyclopedia of Instrumentation for Industrial Hygiene, Univ. of Mich., Inst. of Industrial Health, 626-631.

Gill, G. C.: 1957, 'Heated Thermocouple Anemometers and Light Bivanes - M.I.T', Exploring the Atmosphere's First Mile, Vol. I, Pergamon Press, 233-242.

Gill, G. C.: 1967, 'On the Dynamic Response of Meteorological Sensors and Recorders', Proc. First Canadian Conf. Micrometeorology, Part I, Can. Dept. of Transport, Meteorol. Br., Toronto, 1-27.

Gill, G. C.: 1974, 'The Helicoid Anemometer - a long Neglected but Valuable Anemometer', Atmosphere 11, 146-155.

Gill, G. C., Bradley, J., and Sela, J.: 1967, 'The UVW Anemometer - an Instrument to Measure the Three Orthogonal Wind Vectors Separately and Independently', Paper presented at Am. Meteorol. Soc., Annual Meeting, Ann Arbor, Mich., March, 1967.

Hicks, B. B.: 1972, 'Propeller Anemometers as Sensors of Atmospheric Turbulence', BoundaryLayer Meteorol. 3, 214-228.

Horst, T. W.: 1973a, 'Corrections for Response Errors in a Three-Component Propeller Anemometer', J. Appl. Meteorol. 12, 716-725.

Horst, T. W.: 1973b, 'A Computer Algorithm for Correcting Noncosine Response in the Gill Anemometer', Battelle Northwest Laboratories report, BNWL-1651 PT1.

MacCready, P. B., Jr. and Jex, H. R.: 1964, 'Response Characteristics and Meteorological Utilization of Propellers and Vane Wind Sensors', J. Appl. Meteorol. 3, 182-193.

McBean, G. A.: 1972, 'Instrument Requirements for Eddy Correlation Measurements', J. Appl. Meteorol. 11, 1078-1084.

Michelena, E. O. and Gill, G. C.: 1971, 'An Improved Biaxial Water Meter,' Proc. 14th Conf. Great Lakes Res., 681-689.

Schubauer, G. B., and Adams, G. H.: 1954, 'Lag of Anemometers', NBS Report 3245, 16 pp. 